\title{
Kalman filter based data fusion for neutral axis tracking in wind turbine towers
}

\author{
Soman, Rohan; Malinowski, Pawel; Ostachowicz, Wieslaw; Schmidt Paulsen, Uwe
}

Published in:

Health Monitoring of Structural and Biological Systems 2015

Link to article, DOI:

$10.1117 / 12.2084145$

Publication date:

2015

Document Version

Publisher's PDF, also known as Version of record

Link back to DTU Orbit

Citation (APA):

Soman, R., Malinowski, P., Ostachowicz, W., \& Schmidt Paulsen, U. (2015). Kalman filter based data fusion for neutral axis tracking in wind turbine towers. In T. Kundu (Ed.), Health Monitoring of Structural and Biological Systems 2015 (Vol. 9438, pp. 94381B). SPIE - International Society for Optical Engineering. Proceedings of SPIE - The International Society for Optical Engineering https://doi.org/10.1117/12.2084145

\section{General rights}

Copyright and moral rights for the publications made accessible in the public portal are retained by the authors and/or other copyright owners and it is a condition of accessing publications that users recognise and abide by the legal requirements associated with these rights.

- Users may download and print one copy of any publication from the public portal for the purpose of private study or research.

- You may not further distribute the material or use it for any profit-making activity or commercial gain

- You may freely distribute the URL identifying the publication in the public portal 


\title{
Kalman filter based data fusion for neutral axis tracking in wind turbine towers
}

\author{
Rohan Soman*a, Pawel Malinowski ${ }^{\mathrm{a}}$, Wieslaw Ostachowicz ${ }^{\mathrm{a}, \mathrm{b}}$, Uwe Schmidt Paulsen ${ }^{\mathrm{c}}$ \\ ${ }^{a}$ Polish Academy of Sciences, Institute of Fluid-Flow Machinery, Fiszera 14 Street, 80-231, \\ Gdansk, Poland; ${ }^{\mathrm{b}}$ Warsaw University of Technology, Faculty of Automotive and Construction \\ Machinery, Narbutta 84, 02-524 Warsaw, Poland; ' Department of Wind Energy, Technical \\ University of Denmark, Frederiksborgvej 399,DK-4000, Roskilde
}

\begin{abstract}
Wind energy is seen as one of t he most promising solutions to man's ever increasing demands of a clean source of energy. In particular to reduce the cost of energy (COE) generated, there are effo rts to increase the life-time of the wind turbines, to reduce maintenance costs and to ensure high availability.

Maintenance costs may be lowered and the high availability and low repair co sts ensured through the use of condition monitoring (CM) and structural health monitoring (SHM). SHM allows early detection of damage and allows maintenance planning. Furthermore, it can allow us to avoid unnecessary downtime, hence increasing the availability of the system.

The present work is based on the use of neutral axis (NA) for SHM of the structure. The NA is tracked by data fusion of measured yaw angle and strain through the use of Extended Kalman Filter (EKF). The EKF allows accurate tracking even in the presence of changing ambient conditions. NA is defined as the line or plane in the section of the beam which does not experience any tensile or compressive forces when loaded. The NA is the property of the cross section of the tower and is ind ependent of the applied loads and ambient conditions. Any change in the NA position may be used for detecting and locating the damage. The wind turbine tower has been modelled with FE so ftware ABAQUS and validated on data from load measurements carried out on the $34 \mathrm{~m}$ high tower of the Nordtank, NTK 500/41 wind turbine.
\end{abstract}

Keywords: Structural Health Monitoring (SHM), Damage Detection, Wind Turbine Tower, Neutral Axis (NA), Kalman Filter (KF), Data Fusion, Strain

\section{INTRODUCTION}

Wind energy is seen as one of the most promising solutions to man's ever increasing demands of a clean source of energy. The use of wind energy has received an impetus due to the advancements in the field of materials engineering. Newer, bigger wind turbines are now possible which are more robust, and lighter in weight. The main drawback of the wind energy is the high initial costs for setting up and maintenance. These high initial cost make the energy more expensive than the conventional energy sources like fossil fuels and nuclear and hence has not been widely accepted. The cost of generation being the biggest drawback of wind energy, there is a concerted effort to reduce it. This can be achieved by increasing the life-time of the wind turbines; reducing maintenance costs and ensuring high availability. The lifetime may be increased by ensuring a more robust design while the maintenance cost may be lowered and the high availability ensured through the use of condition monitoring (CM) and structural health monitoring (SHM) [1]. SHM allows early detection of damage and allows maintenance planning which reduces the cost [2]. Furthermore, it can allow us to avoid unnecessary downtime, hence increasing the availability of the system. The SHM needs to be low cost, and suitable for continuous monitoring. These techniques are based on the concept that, the change in mechanical properties of the structure will be captured by a change in its dynamic characteristics [3]. The SHM process involves the observation of a system over time using periodically sampled dynamic response measurements from an array of sensors, followed by the extraction of damage-sensitive features from these measurements, and the statistical analysis of these feature $\mathrm{s}$ to determ ine the current state of the system's health. The SHM process requires use of sensors for data collection, filters for data cleansing, and central data processing units for feature extraction and post processing.

Some of the SHM methods investigated have been able to detect and locate damage in a laboratory environment under controlled conditions. However when these methods were implemented for field validations or in real structures, the results obtained were no $t$ up to the desired level. The discrepancy between the expected and the measured results are mainly attributed to the uncertainty in the measurement environment with respect to noise, 
temperature and excitation mechanism for the structure. Hence the SHM system should be able to detect small levels of damage but at the same time, robust enough to overcome the ambient noise and temperature changes and detect damage under operational conditions.

In this paper, the performance of the Neutral Axis (NA) tracking through the use of Kalman filter ( $\mathrm{K} \quad \mathrm{F})$ [4] proposed in $[5,6]$ is validated through experimental data. The position of Neutral Axis (NA) of the tower structure is tracked using the actual measured strain data from the Nordtank NTK 500/41 turbine [7]. It is shown that in the absence of axial strains, the NA tracked is i ndependent of the yaw angle which is expected as NA is the property of the cross section of the tower independent of the bulk temperature effects, and the ambient loading. The position of the neutral axis can be assessed by measuring the strains on opposite surfaces of the tower in bending. The performance of the direct estimation method and the KF based tracking is compared, and once the KF based method is proven to be $\mathrm{m}$ ore precise, it is used for damage detection in the validated simulated FE model of the Nordtank NTK 500/41 tower (Figure 1).

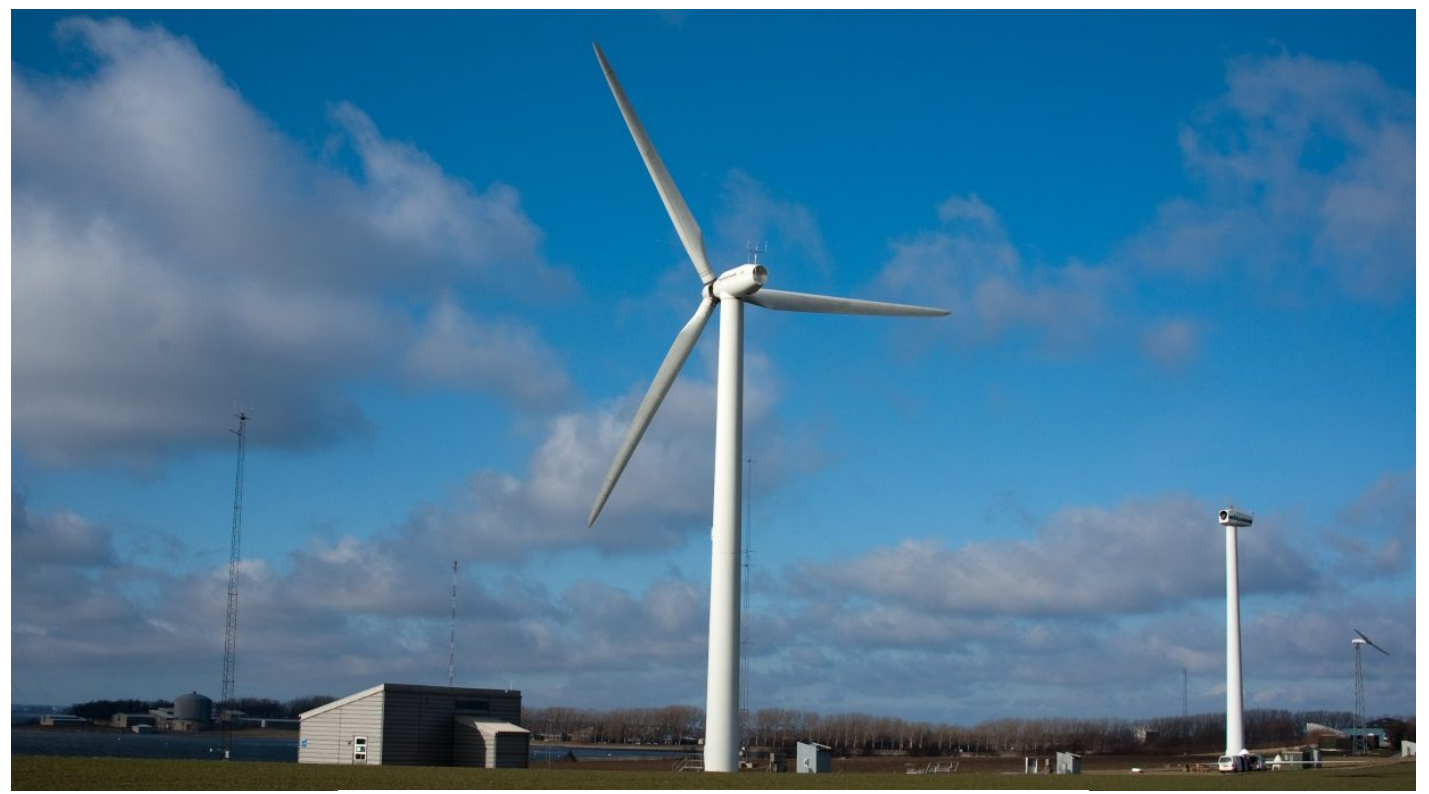

Figure 1: Wind Turbine NTK 500/41

\section{THEORETICAL BACKGROUND}

\subsection{Neutral Axis}

Wind loads applied on a beam-like tower structure will lead to bending strains in the beam. The bending stresses are given by (1)

$\epsilon=\frac{M_{B} y}{E I}$

Where, $\varepsilon$ is the longitudinal strain in bending, $M_{b}$ is the bending moment at the cross section, $E$ is the Young's modulus and $I$ is the area moment of Inertia, $y$ is the distance from the NA [8].

Also, the strain in bending will have tensile strain at one of the surfaces (left in figure 2), and compressive strain at the opposite surface (right in figure 2). In between, this left and right surface is the neutral axis, of the section. The neutral axis of the section is a function of the flexural rigidity of the structure, and does not depend on the applied bending loads, thus by, measuring the strains at the opposite edges of the beam, the neutral axis can be located, using (2) which in turn may be an indicator of the damage.

$$
N A=\frac{\varepsilon_{l}}{\varepsilon_{r}+\varepsilon_{l}}=\frac{y_{n}}{w}
$$

The NA can thus be estimated based on the strain measurements. 


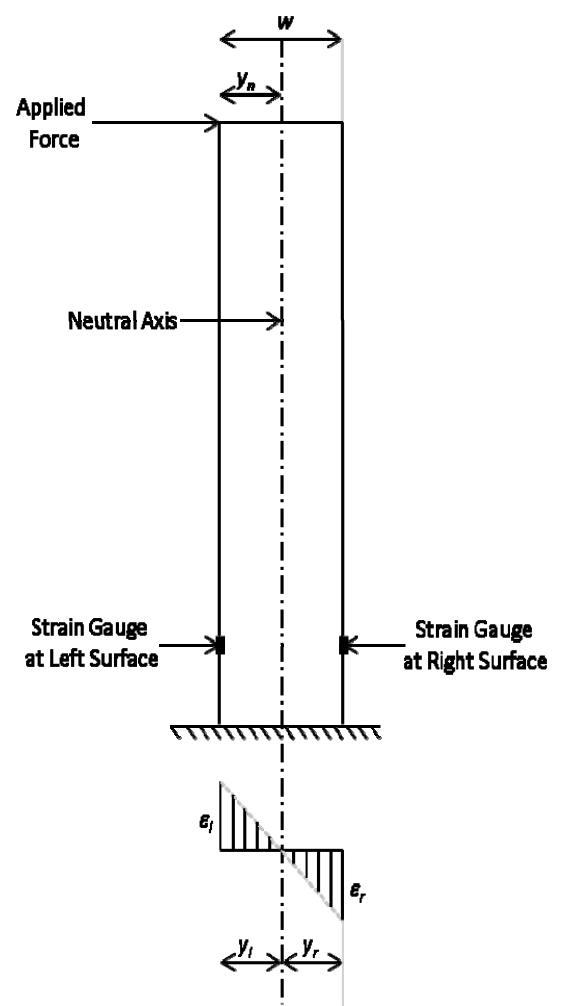

Figure 2: Flexural Strain Distribution over the beam cross-section [5]

\subsection{Kalman Filter (KF)}

The KF is a set of mathematical equations that provides an efficient computational (recursive) solution of the leastsquares method.

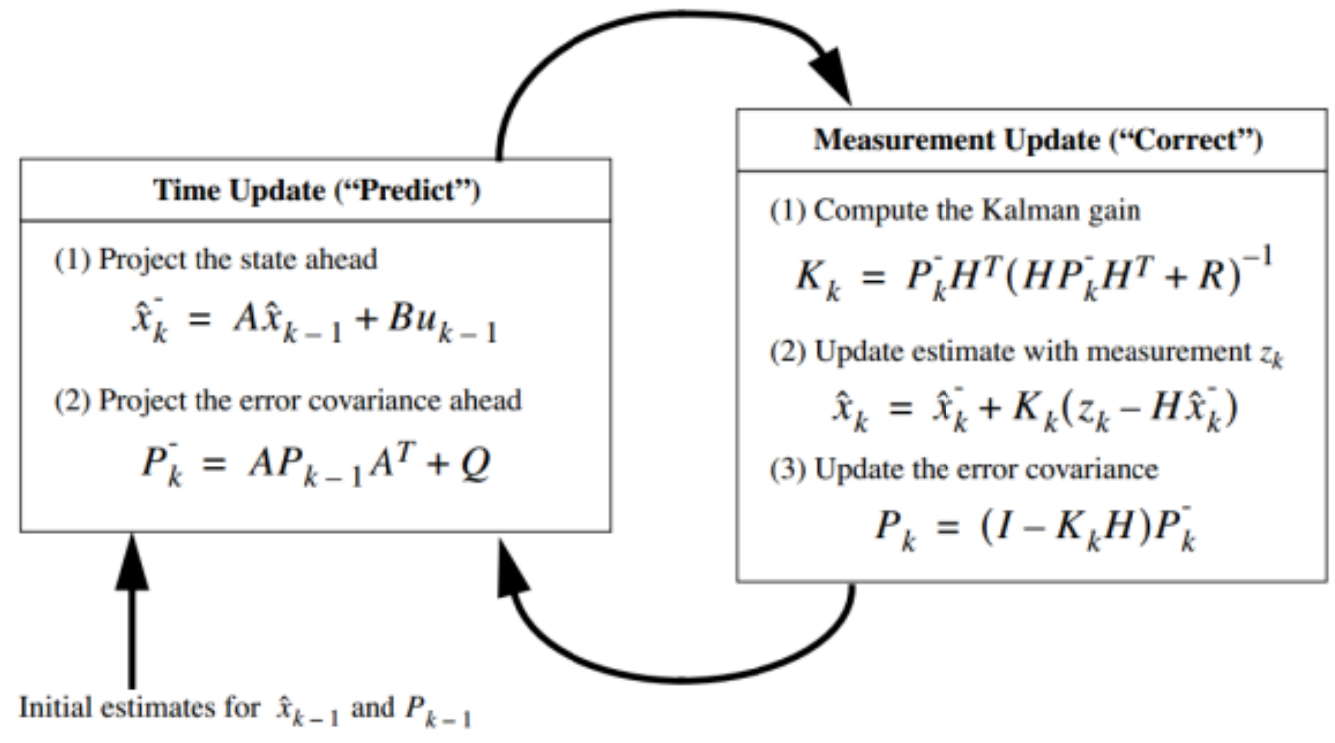

Figure 3: Flow Chart for the implementation of the KF [4]

where, $x$ is the estimate of the state, $A$ is the state transition matrix, $B$ is the control matrix, $u$ is the control variable, $P$ is the state variance matrix, $Q$ is the process variance matrix, $K$ is the Kalman gain, $H$ is the measurement matrix, $z$ is the measurement variable, the 'super minus' indicates a priori estimate while the subscripted $k$ indicates the time step. 
Theoretically, KF combines a system's dynamic model (physical laws of motion) and measurements (sensor readings) to form an estimate of the systems varying quantities (system state) that is better than the estimate of the system obtained by measurement alone [9]. Figure 2 concisely explains the implementation of the Kalman Filter.

In the present application, the state estimate variable is a $2 \times 1$ vector consisting of the, ratio, $\frac{y_{n}}{w}$ which in undamaged condition should remain constant independent of the applied loads and the other variable tracking the constant 1 . This constant for tracking 1 is incorporated to ensure, accurate system depiction, and formation of square measurement matrix which allows faster computations.

\section{DESCRIPTION OF EXPERIMENTAL FACILITY}

The test wind turbine, which is located at Riso Campus, Roskilde, is a traditional Danish three-bladed stall regulated Nordtank, NTK 500/41 wind turbine (Figure 1) - see specifications in Table 1.

Table 1. Nordtank NTK 500/41 specifications [7]

\begin{tabular}{|l|l|}
\hline Rotor & \\
\hline Rotor Diameter & $41.1 \mathrm{~m}$ \\
\hline Swept area & $1320 \mathrm{~m}^{2}$ \\
\hline Rotational Speed: & $27.1 \mathrm{rpm}$ \\
\hline Measured tip angle: & $-0.2^{\circ} \pm 0.2^{\circ}$ \\
\hline Tilt & $2^{\circ}$ \\
\hline Coning & $0^{\circ}$ \\
\hline Blades & \\
\hline Blade type: & LM 19.1 \\
\hline Blade profile[s] & NACA $63-4 \mathrm{xx}$ \& NACA FF-W3, equipped with vortex generators. \\
\hline Blade length: & $19.04 \mathrm{~m}$ \\
\hline Blade chord: & $0.265-1.630 \mathrm{~m}$ \\
\hline Blade twist: & $0.02-20.00$ degrees \\
\hline Air brakes & Pivotal blade tips, operated in FS-mode \\
\hline Wind Turbine & \\
\hline 8 Risø-R-1593(EN) & \\
\hline Mechanical brake & High speed shaft, operated in FS-mode \\
\hline Power regulation & Passive aerodynamic stall \\
\hline Gearbox & Flender; ratio $1: 55.35$ \\
\hline Generator & Siemens $500 \mathrm{~kW}, 4$ poles, $690 \mathrm{~V}$ \\
\hline Tower & \\
\hline Type Conical steel tube, & $33.8 \mathrm{~m}$ \\
\hline Hub height & $36.0 \mathrm{~m}$ \\
\hline Masses: & \\
\hline Blade weight: & $1960 \mathrm{~kg}$ \\
\hline Rotor incl. hub & $9030 \mathrm{~kg}$ \\
\hline Tower head mass & $24430 \mathrm{~kg}$ \\
\hline Tower mass & $22500 \mathrm{~kg}$ \\
\hline
\end{tabular}

The wind turbine is instrumented with a variety of sensors on the blades, in the gearbox and on the tower for measuring the different response of the structure and the ambient conditions like strain, the acceleration response to wind loading, the wind speed and direction, the yaw angle, temperature etc. Some of these sensors, namely the strain sensors at the bottom of the tower, the wind speed and direction sensors and the yaw angle measurements have been used for the validation of the methodology. The type of the sensor and its brief description is given in Table 2 . 
Table 2. Relevant Sensor Specifications [7]

\begin{tabular}{|l|l|l|l|l|}
\hline Measurement & Sensor & $\begin{array}{l}\text { Signal } \\
\text { type }\end{array}$ & Conversion Principle & Transmitter \\
\hline $\begin{array}{l}\text { Wind speed } \\
\text { nacelle }\end{array}$ & $\begin{array}{l}\text { Risø cup anemometer } \\
\text { P2546A } \\
\text { with Reed relay }\end{array}$ & Digital & $\begin{array}{l}\text { 2 magnets on turning } \\
\text { shaft controls the contact } \\
\text { closure timings of the } \\
\text { relay per revolution }\end{array}$ & $\begin{array}{l}\text { Risø P2858A } \\
\text { DAU Configured } \\
\text { to periodic time } \\
\text { measurement }\end{array}$ \\
\hline $\begin{array}{l}\text { Wind direction } \\
\text { nacelle }\end{array}$ & $\begin{array}{l}\text { Vector Wind vane } \\
\text { F2819A }\end{array}$ & Analogue & $\begin{array}{l}\text { Measuring on resistive } \\
\text { viper } \\
\text { path relative to one full } \\
\text { turn }\end{array}$ & Voltage divider \\
\hline $\begin{array}{l}\text { Tower Bottom } \\
\text { Xending moment }\end{array}$ & $\begin{array}{l}\text { Micro Measurement } \\
\text { Strain } \\
\text { Gauge CEA-06-250C- } \\
\text { 350 }\end{array}$ & Analogue & $\begin{array}{l}\text { Semiconductor foil } \\
\text { subjected to resistive } \\
\text { change due to bending }\end{array}$ & $\begin{array}{l}\text { Risø P2912B SG } \\
\text { Amplifier }\end{array}$ \\
\hline $\begin{array}{l}\text { Tower bottom } \\
\text { bending } \\
\text { moment Y }\end{array}$ & $\begin{array}{l}\text { Micro Measurement } \\
\text { Strain } \\
\text { Gauge CEA-06- } \\
\text { 250UW-350 }\end{array}$ & Analogue & $\begin{array}{l}\text { Semiconductor foil } \\
\text { subjected to resistive } \\
\text { change due to bending }\end{array}$ & $\begin{array}{l}\text { Risø P2912B SG } \\
\text { Amplifier }\end{array}$ \\
\hline $\begin{array}{l}\text { Position of } \\
\text { nacelle }\end{array}$ & $\begin{array}{l}\text { Resistor with gearbox } \\
\text { attached to yaw drive }\end{array}$ & Analogue & $\begin{array}{l}\text { Measuring on resistive } \\
\text { path }\end{array}$ & Voltage divider \\
\hline
\end{tabular}

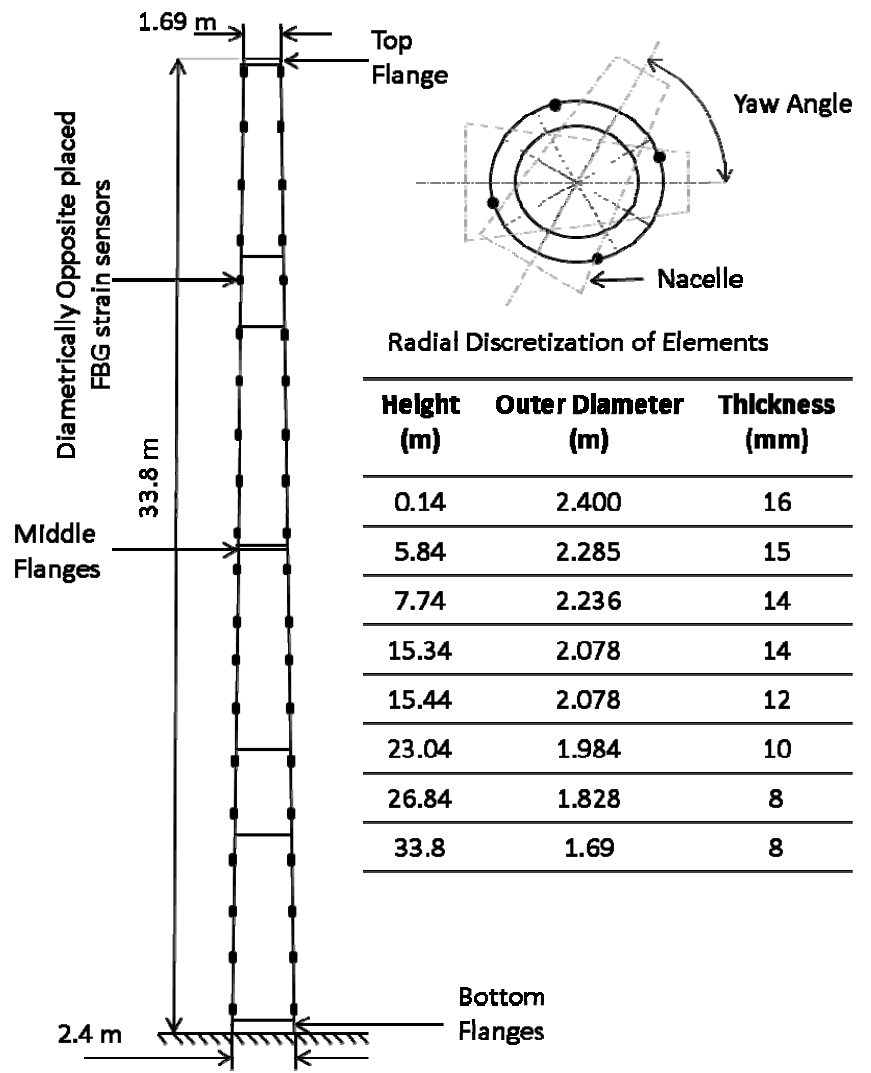

Figure 4: FE modelling details of Tower

In addition a FE model of the wind turbine tower was created in commercial software ABAQUS [10] using the design drawings available. The tower is a hollow tubular steel structure $33.8 \mathrm{~m}$ high. It is made of 2 tubes connected end to end 
with flanges. The outside diameter of the tower varies linearly from $2.4 \mathrm{~m}$ at the base to $1.69 \mathrm{~m}$ at the top. The model was validated using the bending moment experienced under certain loading conditions and also the natural frequencies of the tower. The bending moments for the loading and the natural frequencies were in decent agreement and this validated $\mathrm{FE}$ model in Figure 4 is used for the validation of the detection of damage using NA tracking.

The tubular sections of the tower are made from steel RSt-37-2 while the flanges are made from St- 52-3. The nacelle and hub loads were applied as point loads, at specified eccentricity and height indicated from the design specifications. The wind loads were simulated as random loads using Euro-codes [11]. The velocity measurements at the hub was used and varied with the height of the according to the power and applied on the surface area facing the wind, The blades, however, were assumed to be pitched into a full aerodynamic brake position to ensure minimal rotor motion and consequent change in mass distribution, which may affect the NA [12].

\section{RESULTS}

\subsection{Experimental Validation}

The proposed methodology was validated using actual bending moments measured at two relatively perpendicular axes. In addition the yaw angle measurement was also used for studying the effect it has on the NA estimation. It has to be noted that the strain sensors for the bending moment measurement are put in the Full Bridge type II [13] configuration and hence measure the bending strain only. The NA axis estimates under two conditions constant yaw angle and changing yaw angle are provided to show the robustness of the proposed methodology. The wind turbine tower is known to be in healthy condition, and in the absence of any axial; loads the neutral axis estimate is expected to be 0.5 along both axes owing to the symmetry of the structure.

The KF is a powerful tool for the estimation of the state variables especially in the presence of measurement noise. So, the use of KF will improve the estimation. Figure 5 and 6 shows the relative performance of the KF for the NA estimation compared to the direct estimation method in two different conditions, namely, constant yaw angle and changing yaw angle. Figure 7 gives the statistical performance of the estimation methods.

As can be seen in the figures, the KF estimate of NA is more stable than the direct estimation. The direct estimation of NA may lead to false negative detection of damage when the measured strain is low and the noise in the measurement become significant.
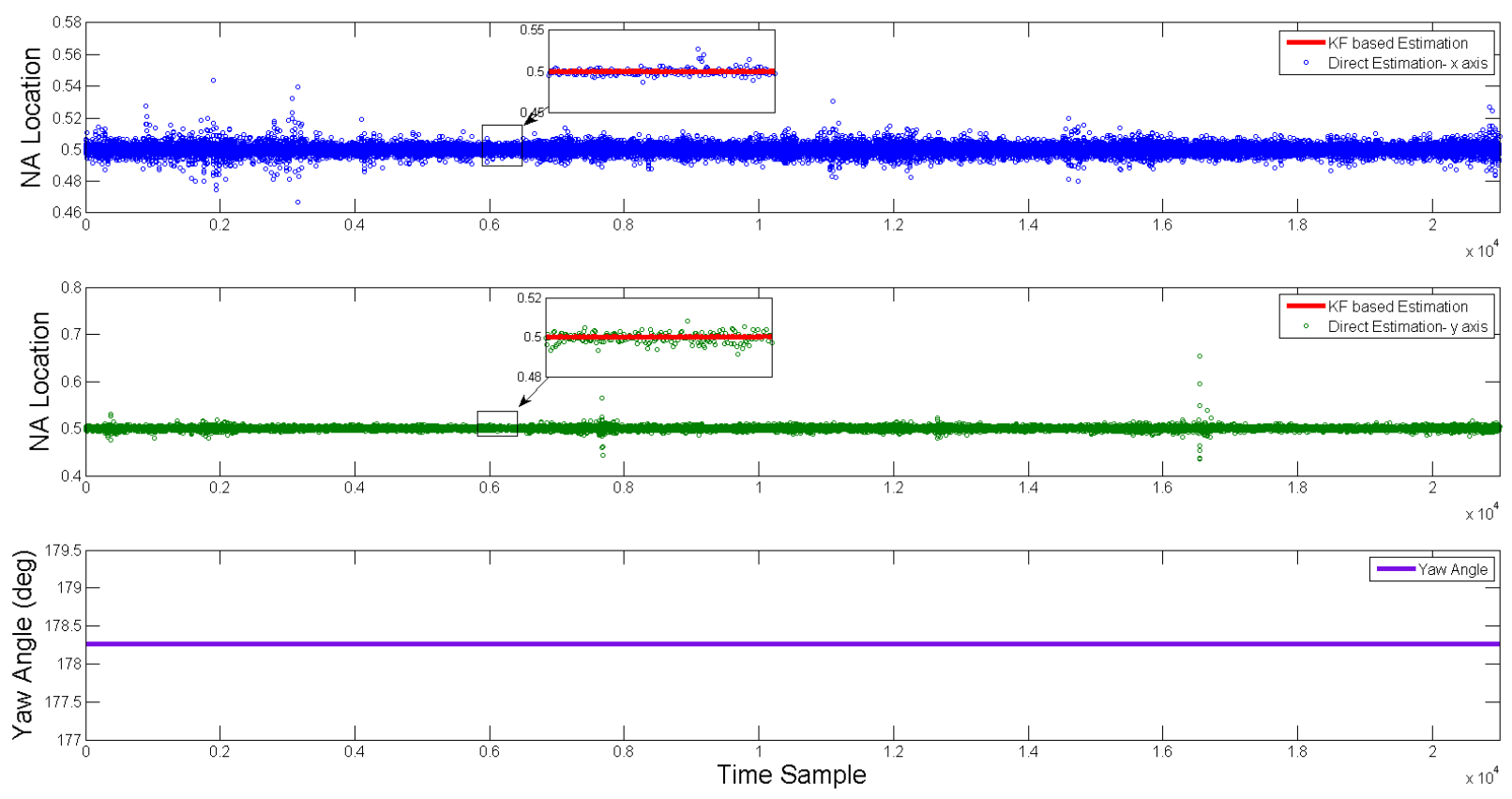

Figure 5: Comparison between direct estimation and KF estimation (Constant Yaw) 

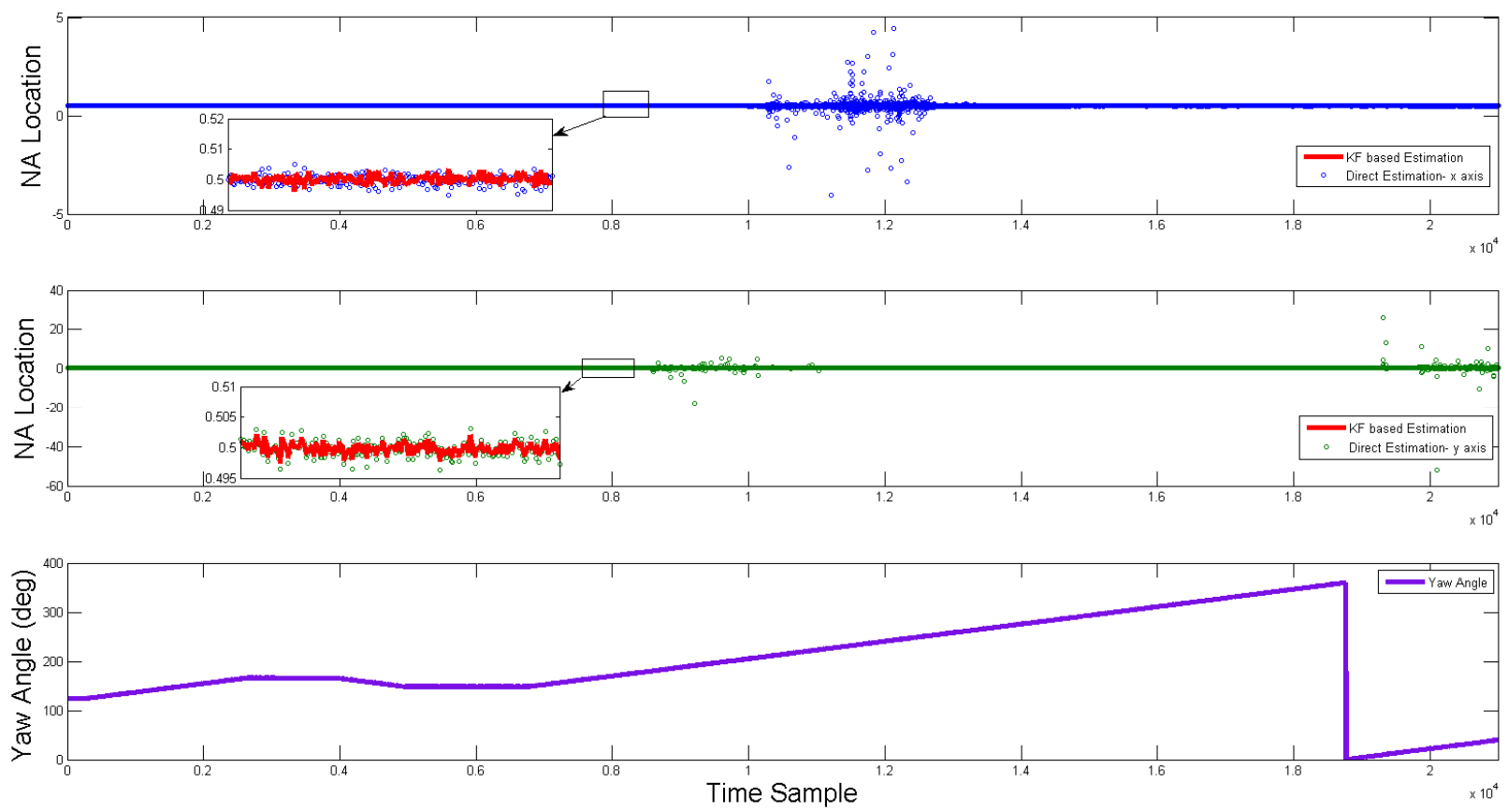

Figure 6: Comparison between direct estimation and KF estimation (Changing Yaw)

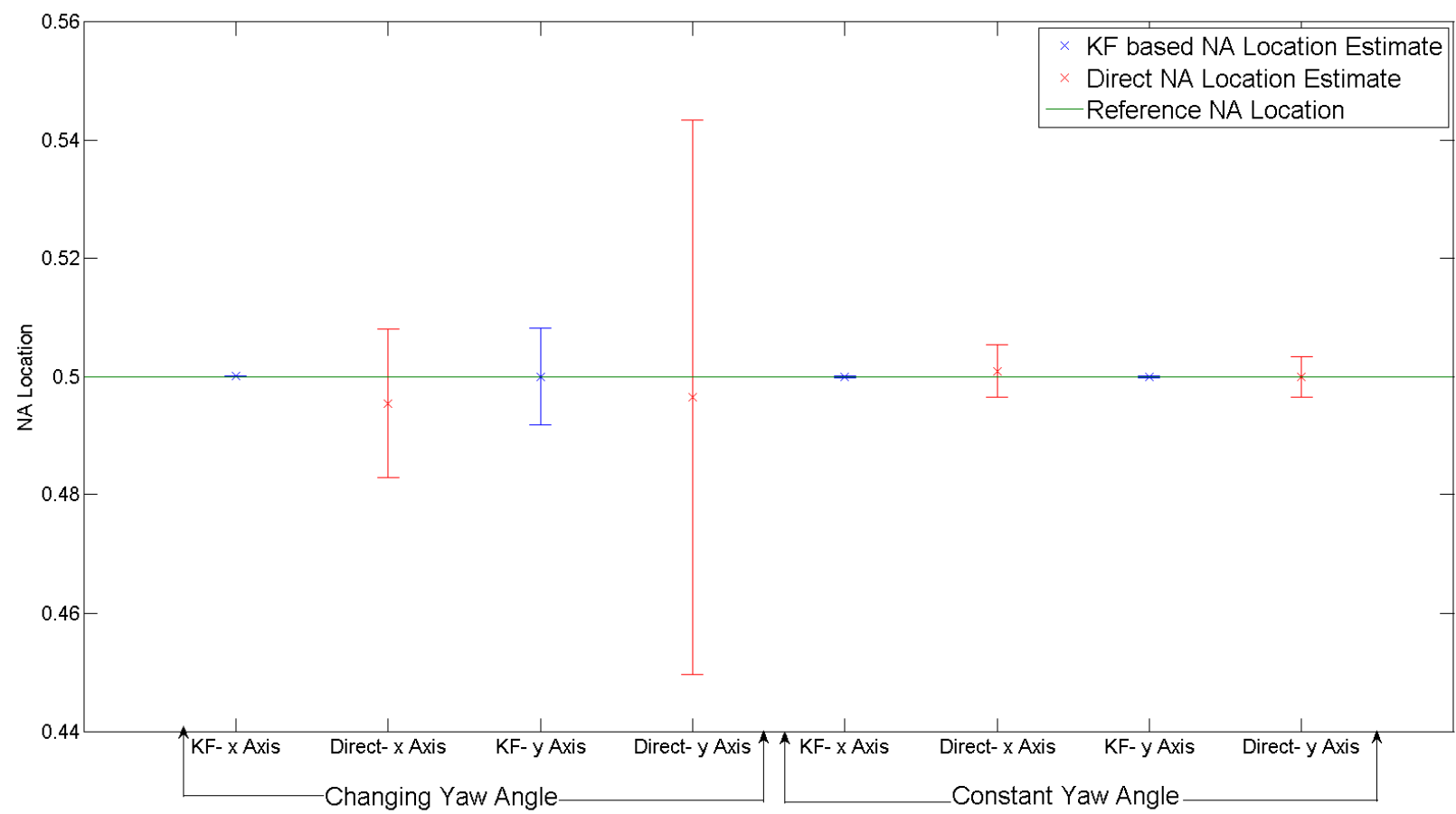

Figure 7: Statistical Comparison of performance of direct estimation and KF estimation

The standard deviation of the KF based estimation is orders of magnitude lower than the direct estimation method, even when there is yawing of the nacelle. Also, due to the presence of measurement noise, the mean of the prediction of the direct estimation method changes, this in turn will affect the accuracy of the damage detection methodology. Hence, the use of Kalman Filter estimator is necessary in order to have lower threshold for damage detection alarms and hence make detection of smaller levels of damage possible. It can also be noticed that the NA estimation along $y$ axis has a higher dispersion than in the case of $x$ axis. This can be attributed to the orientation of the nacelle. The orientation of the 
nacelle imposes higher strains in the $\mathrm{x}$-direction and as such the contribution of the noise in the measurements is considerably lower. As the strain levels go lower, the contribution of the measurement noise is more significant causing the dispersion.

\subsection{NA based Damage Detection}

As explained in section 2.1, the NA of the cross-section of the tower is the property of the condition of the structure and in the normal working conditions remains unaffected, by the applied loads and the noise corruption in the measurement. So, the NA may be used as a damage indicator.

In order to validate this, artificial damage was introduced in one element of the tower, by reduction of the flexural rigidity of that particular element by $20 \%$ Reduction of Flexural Rigidity is a valid damage simulation strategy as indicated by [14]. The reduction of flexural rigidity may be treated equivalent to loss of material thickness due to corrosion or cracking and is a commonly used strategy for global level damage simulation in bridge structures [15]. The simulated damage was detected by comparing the NA estimate of the damage and the undamaged element. For the study, and bearing in mind the multiplexing benefit of FBG sensors, two lines of 22 sensors were assumed at diametrically opposite locations along the tower as shown in Figure 3.

The damage is detected if the change in the NA estimation of the damaged and undamaged state is more than a specified threshold, which is determined on engineering judgment.

The table 3 shows the change in NA because of reduction of the flexural rigidity of element of the tower by $20 \%$. It can be clearly seen that the change in the location of NA in the damaged element is quite considerable as compared to any other location along the tower. In addition by taking the inverse tangent function of the ratio of the change in the location along the two axes, and using the sign of the change into consideration, the damaged element can be located accurately. This methodology is discussed in more detail in [6]

Table 3: Damage Detection for $20 \%$ reduction in flexural rigidity

\begin{tabular}{ccccccc}
\hline \multicolumn{7}{c}{ Damage Scenario: Damage in the lower part of the tower } \\
\hline Sensor & Undamaged & Xamaged & \% change & Undamaged & Damaged & \% change \\
Location & NA estimate & NA & in & NA estimate & NA & in \\
& & estimate & estimate & & estimate & estimate \\
\hline 1.6 & 0.5000 & 0.5003 & -0.0681 & 0.5000 & 0.5002 & -0.0386 \\
$\mathbf{3 . 2}$ & $\mathbf{0 . 5 0 0 0}$ & $\mathbf{0 . 5 0 7 3}$ & $\mathbf{- 1 . 4 6 5 4}$ & $\mathbf{0 . 5 0 0 0}$ & $\mathbf{0 . 5 0 4 2}$ & $\mathbf{- 0 . 8 3 0 9}$ \\
4.8 & 0.5000 & 0.5009 & -0.1799 & 0.5000 & 0.5005 & -0.1020 \\
6.4 & 0.5000 & 0.5000 & 0.0039 & 0.5000 & 0.5000 & 0.0022 \\
8.0 & 0.5000 & 0.4999 & 0.0150 & 0.5000 & 0.5000 & 0.0085 \\
9.7 & 0.5000 & 0.4999 & 0.0150 & 0.5000 & 0.5000 & 0.0085 \\
11.3 & 0.5000 & 0.5000 & 0.0099 & 0.5000 & 0.5000 & 0.0056 \\
12.9 & 0.5000 & 0.5000 & 0.0056 & 0.5000 & 0.5000 & 0.0032 \\
14.5 & 0.5000 & 0.5000 & 0.0023 & 0.5000 & 0.5000 & 0.0013 \\
16.1 & 0.5000 & 0.5000 & -0.0002 & 0.5000 & 0.5000 & -0.0001 \\
17.7 & 0.5000 & 0.5000 & -0.0036 & 0.5000 & 0.5000 & -0.0020 \\
19.3 & 0.5000 & 0.5000 & -0.0024 & 0.5000 & 0.5000 & -0.0014 \\
20.9 & 0.5000 & 0.5000 & -0.0017 & 0.5000 & 0.5000 & -0.0010 \\
22.5 & 0.5000 & 0.5000 & -0.0013 & 0.5000 & 0.5000 & -0.0007 \\
24.1 & 0.5000 & 0.5000 & -0.0008 & 0.5000 & 0.5000 & -0.0004 \\
25.8 & 0.5000 & 0.5000 & -0.0006 & 0.5000 & 0.5000 & -0.0003 \\
27.4 & 0.5000 & 0.5000 & -0.0004 & 0.5000 & 0.5000 & -0.0002 \\
29.0 & 0.5000 & 0.5000 & -0.0003 & 0.5000 & 0.5000 & -0.0002 \\
30.6 & 0.5000 & 0.5000 & 0.0002 & 0.5000 & 0.5000 & 0.0001 \\
32.2 & 0.5000 & 0.5000 & 0.0005 & 0.5000 & 0.5000 & 0.0003 \\
\hline
\end{tabular}




\section{CONCLUSIONS}

The paper proposes NA tracking as a damage indicator. The study first establishes the merits for the use of KF for NA tracking estimation on real data from the Nordtank 500/41 wind turbine. This KF based NA estimation is then used to detect damage in the simulated tower structure of the wind turbine.

The study indicates that the NA is a property of the condition of the structure and remains relatively unaffected by the measurement noise, and the ambient condition changes. Furthermore, in the present configuration of the sensors where the strain sensors are immune to axial loading, the yaw of the nacelle does not affect the NA location. From the results obtained it can be seen that the NA based tracking is a promising SHM methodology which promises to be low cost. Furthermore, it is sensitive to lower levels of damage which are not detected through the conventional vibration based methods.

The present study aims at validating the location of NA tracking using KF based on real data from the wind turbine. The authors acknowledge that more sensitivity studies need to be undertaken for deciding the thresholds which indicate damage detection. Furthermore, more data collected over a long time is needed in order to see the deterioration of the condition of the structure and hence has been earmarked as an area of further research. Also the effect of temperature changes, both diurnal and seasonal may affect the strains in the system, and its effect has to be studied in detail. In addition more realistic damage scenarios, like fatigue induced cracks, need to be simulated and the sensitivity of the method needs to be validated in the scenarios.

In nutshell, the study presents a brief study and a proof of concept of the robustness of NA tracking on real wind turbine data. The obtained simulated results also show promise and as such, may be employed on selected structures for validation.

\section{ACKNOWLEDGMENTS}

The authors would like to acknowledge the European Commission for their research grant under the project FP7PEOPLE-20120ITN 309395 "MARE-WINT" (new Materials and REliablity in offshore WINd Turbines technology). The authors are also grateful to TASK-CI for allowing the use of their computational resources. The opinions expressed in this paper do not necessarily reflect those of the sponsors.

\section{REFERENCES}

[1] Chy S., Park, J., Jung, H-J., Yun, C-B., Jang, S., Jo, H., Spencer Jr, B.F., Nagayma, T., Seo, J.W., 2010, “Structural health monitoring of cable-stayed bridge using acceleration data via wireless smart sensor network", Bridge Maintenance, Safety, Management and Life Cycle Optimization. pp 158-164

[2] Doebling, S.W., Farrar, C.R., Prime, M.B., "A Summary Review of Vibration based Damage Identification Techniques", Shock and Vibration Digest, 30(2) 91-105 (1998)

[3] Abedwuyi, A., Wu, Z., Serker, N. H. K. M., "Assessment of Vibration-based Damage Identification Methods using Displacement and Distributed Strain Measurement", Structural Health Monitoring 8(6) 443-461 (2009)

[4] Welch, Greg, and Gary Bishop. "An introduction to the Kalman filter." 1995. [online on 24/01/2014 at http://clubs.ens-cachan.fr/krobot/old/data/positionnement/kalman.pdf]

[5] Soman R., Malinowski, P., Ostachowicz, W., "Neutral Axis Tracking for damage detection in Wind Turbine Towers", EWEA 2014, Barcelona, Spain, 10-14 March 2014

[6] Soman R, Malinowski P, Ostachowicz W, Kalman-Filter Based Data Fusion for Neutral Axis Tracking for Damage Detection in Wind-Turbine Towers, Proceedings of $7^{\text {th }}$ European Workshop of Structural Health Monitoring Vol.20 No.02 - The e-Journal of Nondestructive Testing pp-245-252.

[7] Schmidt Paulsen, U. (2011). Work Package 1B. 2 under the European Commission, Integrated Wind Turbine Design (UPWIND): Verification of long-term load measurement technique.

[8] Xia, H. W., Y. Q. Ni, and X. W. Ye. "Neutral-axis position based damage detection of bridge deck using strain measurement: formulation of a Kalman filter estimator." Proceedings of the 6th European Workshop on Structural Health Monitoring, Dresden, Germany. 2012.

[9] Brown, R.G., Hwang, P. Y. C., "Introduction to Random Signals and Applied Kalman Filtering," 3rd Edition, John Wiley \& Sons, New York, 1997. 
[10] ABAQUS, Analysis User's manual, version 6.12-3 ed., 2013.

[11]Eurocode NS-EN 1991-1-4; "General actions - Wind actions". Standards Nor-way, 2005+NA: 2009.

[12] Bas, J., Carriveau, R., Cheng, S., \& Newson, T. "Strain Response of a Wind Turbine Tower as a Function of Nacelle Orientation" In BIONATURE 2012, The Third International Conference on Bioenvironment, Biodiversity and Renewable Energies (pp. 12-18), 2012

[13] National Instruments SCXI-1520 user manual, version 372583E-01, (2009), [online accessed 04 February 2015, at http://nees.ucla.edu/doc/manuals/NI/SCXI-1520\%20User\%20Manual.pdf]

[14] Adewuyi, A. P., and Z. S. Wu. "Modal macro-strain flexibility methods for damage localization in flexural structures using long-gage FBG sensors" Structural Control and Health Monitoring 18.3 (2011): 341-360

[15] Talebinejad, Iman, Chad Fischer, and Farhad Ansari. "Numerical Evaluation of Vibration-Based Methods for Damage Assessment of Cable Stayed Bridges" Computer Aided Civil and Infrastructure Engineering 26.3 (2011): 239-251. 